\title{
Estância Turística: a importância do patrimônio arquitetônico para o ensino de projeto
}

Tourist Resort: the importance of the architectural patrimony for the teaching of project

Estancia Turística: la importancia del patrimonio arquitectónico para la enseñanza del proyecto

\author{
Juliana Demarchi Polidoro \\ Mestranda PPGARQ, UNESP, Brasil. \\ judp_arquitetura@hotmail.com
}

Rosío Fernández Baca Salcedo Professora Doutora do PPGARQ, UNESP, Brasil. rosiofbs@faac.unesp.br 



Aos resultados de interação entre ações humanas e paisagem primária que se desenvolve no tempo (...) quanto mais modificado esta a paisagem pelos homens, tanto mais cultural é. As paisagens mais modificadas - povoados são culturais por excelência. Incluso os caçadores e recoletores já modificavam consideravelmente a paisagem no processo de caça ou recoleta, ao acender o fogo, etc. (RAPOPORT, 2003, p. 53).

Tratando-se de contextos históricos é importante a preservação da paisagem cultural nas cidades consideras estâncias turísticas, consequentemente a história, identidade e memória local, pois segundo, Chamma (2016):

O abandono, a descaracterização, a degradação do patrimônio arquitetônico e urbano, além das intervenções errôneas arquitetônicas realizadas em áreas históricas podem levar a perda da identidade, da autenticidade e da função social do patrimônio. Assim, é relevante a formação do arquiteto, especialmente no ensino de projetos arquitetônicos no contexto social (CHAMMA e SALCEDO, 2016, p.48).

Para Muntañola (2000) uma paisagem cultural está povoada de objetos e sujeitos reais. Rapoport destaca que "as paisagens culturais estão compostos por sistemas de lugares, dentro dos que discorrem sistemas de atividades" (2003, p. 53). Tanto a paisagem cultural (lugares e suas senhas) como os sistemas de atividades estão compostos por elementos fixos e semifixos e tem sido criados e habitados por elementos não fixos (principalmente pessoas).

Como interfase entre o individuo e sua coletividade a paisagem cultural sofre consequências de uma ordem cronotopica em equilíbrio instável, incessantemente submetido às forças mais profundas da supervivência de nossa espécie. Entende-se por cronotopo $=$ espaço $\mathrm{x}$ tempo $=$ recorte temporal.

Há que destacar, que um projeto arquitetônico, paisagístico e urbanístico, que não está ainda materializado nem construído, tem uma estrutura cronotopica entre a geografia (física) e a história (social). No entanto, ao ser o cronotopo uma relação entre virtualidade e realidade, uma paisagem realmente construída e usada abre um mundo de possibilidades cronotopicas que podem mudar a arquitetura do projeto original, especialmente se este não é mais que uma proposta técnica sem valor "cultural" artístico ou ético (MUNTAÑOLA, 2000).

Com a topogenese, topos (local) e gênese (criação) - origem do lugar -, analisa-se o contexto histórico a partir de sua gênese e através dos cronotopos criados, compreende-se a evolução da arquitetura presente. Desde sua origem até a contemporaneidade. Compreendendo as três dimensões: estética, ética e ciência que configuram a arquitetura do lugar.

A estética da arquitetura compreende a poética, a retórica e a hermenêutica. Entanto, que a ciência deve abranger todos os conhecimentos teóricos e técnicos necessários para a elaboração do projeto de arquitetura. Seguindo pelos conceitos de Muntañola (2009) podemos descrever: a poética por Robert Venturi, que "é o ponto de articulação entre a razão de ser poético e a estrutura do argumento da obra de arte" (MUNTAÑOLA, 2009, p.21). Essa poética esta na: “[...] beleza dos lugares habitados, em tratados de arquitetura, o conteúdo 
poético do cruzamento da construção com seu habitar. Podemos utilizar a poética como instrumento de análise crítica de uma obra" (MUNTAÑOLA, 2009, p.22). Quanto a retórica, é o que nos descreve os sistemas de composição que se fez a mensagem. Os que se concentram nas estratégias de convencimento e persuasão "[...] os instrumentos ou estratégias da retórica são instrumentos degenerados da lógica [...]" (MUNTAÑOLA, 2009, p.26). E por fim a hermenêutica que se organiza em três dimensões sucessivas: a prefiguração que esta vinculada a ideia [...] do projeto; a configuração que é o ato de construir; e por fim a refiguração que é a releitura de nossas cidades e de todos os lugares que nós habitamos (RICOUER, 2003,p.13).

Quando falamos da ética e direcionamos ao ensino de projetos de arquitetura,

[...] demonstrando aos futuros arquitetos que embora haja o caráter artístico da arquitetura, a postura de criador não deve ser aquela que tudo pode na sua obra artística, mas tem que considerar que sua criação está a serviço de outro indivíduo, ou seja, para quem está sendo criada essa obra (CHAMMA e SALCEDO, 2016, p.58).

E por fim, a ciência fecha a compreensão das dimensões da arquitetura do lugar,

[...] desenvolver projetos de intervenção em áreas históricas o arquiteto requer o conhecimento sobre: preservação, patrimônio histórico, arquitetônico e urbano; centros históricos, cidades históricas e sítios históricos; história da arquitetura e do (...) urbanismo; teorias da restauração e reabilitação, além dos conhecimentos da área de tecnologia, representação gráfica, legislação gráfica, legislação, conforto ambiental, acessibilidade, sustentabilidade, materiais, sistemas construtivos, sistemas prediais, etc. (CHAMMA e SALCEDO, 2016, p.54 e 55).

Assim, analisa-se o contexto histórico a partir de sua gênese - a origem de sua história, representado nas referencias físicas e não físicas, considerando alguns conceitos de Muntañola e cronotopos criados por Ricoeur, compreendendo a evolução da arquitetura na cidade, e propor um projeto dialógico, atendendo à todas necessidades presentes naquele contexto proposto.

Soler (2006, p.19) considera que $o$ arquiteto "é um produtor de cultura, mas de uma cultura imersa em um contexto preciso - é quando seu trabalho adquire sentido. E ainda o mesmo autor enfatiza que nessa relação difícil entre contexto e texto nos dará as diretrizes para pensar uma pedagogia da arquitetura".

Com isso, os contextos históricos relacionados à preservação da sua paisagem cultural enfatizando a denominação de estância à uma cidade, desperta na comunidade cientifica a importância da dialogia com o lugar, podendo assim investir no ensino de projeto de arquitetura. "Aquele que pretende estudar as paisagens terá como primeira tarefa a de ler e 


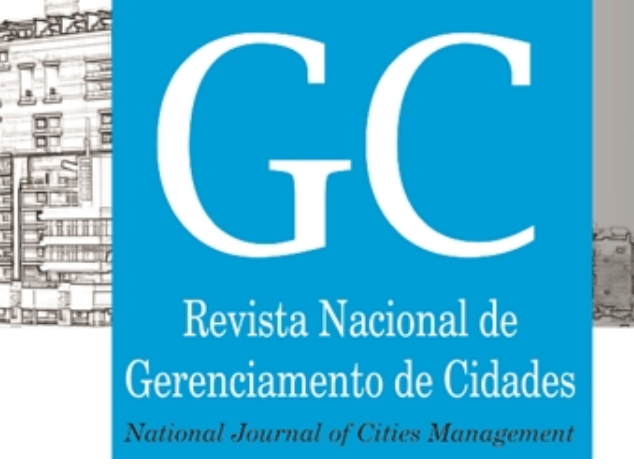

interpretar as formas e as dinâmicas paisagísticas para aprender com elas algo sobre o projeto da sociedade que tem produzido estas paisagens" (BESSE, 2006. p.152).

Um prédio em um contexto histórico de uma estância turística busca:

\begin{abstract}
Na medida em que o patrimônio urbano e arquitetônico é preservado, ele passa a atrair a atração do visitante, que por sua vez, além de valorizar esse patrimônio, pode gerar recursos para a cidade. Para tal, dever-se à criar um plano de desenvolvimento do turismo e uma legislação específica para o centro histórico que terá de conter com as normas sobre o usos do solo, ruídos, trânsito, entre outros. (SALCEDO, 2009, p.71)
\end{abstract}

No ensino de projeto dialógico é fundamental a participação ativa entre o docente e o aluno, numa relação que promove o aprendizado e a reflexão sobre o projeto concebido e seu contexto (SOLER, 2006; FREIRE, 1998).

\title{
2.OBJETIVOS
}

O objetivo do trabalho é propor um método de ensino dialógico do projeto de arquitetura no contexto histórico de estâncias turísticas para Escolas Técnicas do Curso de Desenho de Construção Civil.

\section{METODOLOGIA / MÉTODO DE ANÁLISE}

O método de ensino dialógico do projeto de arquitetura em contextos históricos, em escolas técnicas, tem como base a fundamentação teórica e filosófica de Bakthin, Ricoeur e Muntañola, e das abordagens teóricas de ensino e aprendizagem de Soler (2006), Sanoff (2006) e Freire (1988), que relacionam o texto que é o projeto de arquitetura com seu contexto histórico (Figura 01). 


CONDEPHAAT em 1972 . Justificado pela a afirmação de seu fundador Luiz de Souza Leão: "Creio em Tupan, porque creio em São Paulo, e no seu gigantesco esforço que resulta a atual grandeza do Brasil" (MONTES et al., 2012 , p.91)

Nesta estância turística em questão, seu plano diretor de 2009 já atende as políticas de turismo, para a preservação e conscientização de áreas históricas presentes na cidade de Tupã. Destacando em um de seus objetivos: "buscar o equilíbrio entre as necessidades econômicas e um desenvolvimento turístico, passando pela valorização da vida, através da valorização das comunidades envolvidas e da conservação do meio ambiente" (PLANO DIRETOR DE TUPA, 2009, p.15).

Para os procedimentos metodológicos, as ações didáticas que nortearão as etapas do método proposto, serão divididas em três fases:

a) aula expositiva e dialogada;

b) análise da relação 'texto-contexto' em obras de arquitetura dialógica em contextos históricos; e

c) proposta projetual dialógica, com: programa de necessidades, perfil de usuário e os produtos que devem ser gerados (CHAMMA e SALCEDO, 2016). Porém, de maneira sintetizada afinal, o curso técnico retém uma carga horária bastante condensada, em relação a cursos de graduação.

Inicia-se o método, de maneira interdisciplinar, com a disciplina "História da Produção Arquitetônica e da Paisagem Urbana", em forma de aulas expositivas e seminários, adquirindo assim referencial teórico, tendo subsídios das duas edições do livro "Tupã depoimentos de uma cidade" dos historiadores Arlindo Viselli Montes, Elizabeth Manrique Moreno e lara Bianchi Nakayama (2012). Com esses referenciais históricos e iconográficos da cidade, consegue-se então estabelecer os cronotopos do centro histórico tupãense, assim passa-se para a etapa seguinte do método, já retornando à disciplina projetual.

Soler (2006, p.75) destaca o projeto como,

[...] a atividade poética que coloca a capacidade de produzir uma aprendizagem, não somente a quem a constrói, e sim especialmente a quem a desfruta tanto como espectador, ainda que o objeto imitado seja desconhecido para esse espectador.

A interdisciplinaridade no ensino de projeto acontecerá entre as duas disciplinas no segundo módulo do curso em questão (História da Produção Arquitetônica e da Paisagem Urbana e Projeto Arquitetônico de Edificações) . Na disciplina "História da Produção Arquitetônica e da Paisagem Urbana considerada cem por cento teórica serão inseridos os seguintes conteúdos: 0 edifício e a cidade; processos de urbanização; estilos arquitetônicos e respectivos períodos na história da humanidade; técnicas construtivas utilizadas em diferentes épocas da história, e técnicas construtivas brasileiras, suas origens, influências e características as referências tupãenses ligando-se à disciplina de projeto arquitetônico de edificações I, com o conteúdo 
de: princípios e procedimentos da elaboração de um projeto arquitetônico, e projeto arquitetônico de uma edificação residencial: estudo do terreno.

Já na disciplina "Projeto Arquitetônico de Edificações", considerada pelo plano de ensino como cem por cento prática, o texto é relacionado ao contexto (aluno x projeto). Com auxilio dos métodos de análise do entorno proposto por Sanoff (2006) faz-se a visita no local para levantamento do entorno no terreno proposto pelo professor, analisando: a forma, o traçado, o gabarito projetual, as tipologias arquitetônicas; e o contexto da paisagem cultural presente, com seus mapas sociais e de comportamento em duas etapas distintas que se completam ao final dessa análise poética. Na concepção do projeto em contextos históricos, Chamma e Salcedo, atribuem as seguintes categorias:

\begin{abstract}
Em arquitetura a síntese do heterogêneo é a capacidade do arquiteto em trabalhar com as contradições, com as variáveis projetuais. A inteligibilidade é a compreensão do lugar, sua identidade e seus contextos. Já a intertextualidade em arquitetura é a intenção do arquiteto e o respeito dado a ambiência de edifícios já existentes (entorno) ao se contextualizar com o novo edifício (ou uma nova proposta em um edifício existente). Ao inscrever um novo edifício no espaço construído se estabelece a relação entre inovação e tradição (CHAMMA e SALCEDO, 2016, p. 56, negrito nosso).
\end{abstract}

A primeira etapa da visita, ilustrada na figura 03, representa o entorno do local proposto ao projeto - Rua Goitacazes, na região central em uma rua com características de prédios mistos residências e serviços (clinicas médicas) - com a análise da gênese dos edifícios e as condições e características atuais, destacando a importância desses prédios para o contexto histórico da região central da cidade de Tupã. Sendo eles: Hospital São Francisco de 1959, Grande Hotel Tamoios 1959, Agência dos Correios 1949, Paróquia de São Pedro Apóstolo em 1936, transformando em Matriz de São Pedro após reformas 1958, primeiro grupo escolar - Escola Olavo Bilac 1949, os museus Solar Luiz de Souza Leão 1933 e Museu Histórico e Pedagógico Índia Vanuíre (1965). 


superior moradia) gerando uma diversidade cultural em vários períodos do dia, com o gabarito de altura, materiais e estilos respeitados. Valorizando a cultura, a identidade e a memória da cidade, além do patrimônio arquitetônico.

\section{CONCLUSÃO}

O ensino de projeto de arquitetura em contextos históricos das estâncias turísticas, esta sendo cada vez mais necessário ser aplicado à todas instituições de ensino, tanto de nível médio (técnico) e como de nível superior (graduação), pois o método proposto busca conter a descaracterização e perda da qualidade da paisagem cultural das cidades, valorizando assim, o patrimônio da paisagem cultural, a história, a identidade, à memória. Com isso, o método de ensino dialógico do projeto de arquitetura em escolas técnicas direciona o olhar do discente para a história da cidade com seus patrimônios culturais e arquitetônicos, ensinando a concepção do projeto arquitetônico como resposta às necessidades e expectativas dos usuários (cidadãos e turistas), dialogando com o contexto existente não perdendo suas origens.

\section{REFERÊNCIAS}

BAKHTIN,Mikkail.Estéticadacriaçãoverbal.2.ed.SãoPaulo:Martins Fontes, 1997

BESSE, J. M. Las cinco puertas del paisaje: ensayo de una cartografía de las problemáticas paisajeras contemporáneas. In: MADERUELO, J. (Org.). Paisaje y pensamiento. Madrid: Abada, 2006. p. 145-171.

BRASIL, São Paulo. Lei complementar no 1.261, de 29 de abril de 2015. Lex : Estabelece condições e requisitos para a classificação de Estâncias e de Municípios de Interesse Turístico e dá providências correlatas, São Paulo. DOE-I 30/04/2015, p. 1 .Disponível em: http://www.al.sp.gov.br/norma/?id=174594. Acesso em 10 de agosto de 17.

CEntro estadual de educAÇÃo tecnológica paUla SOUZA. Plano de Curso Técnico em Desenho de Construção Civil, São Paulo, 2011.

CHAMMA, Paula Valéria Coiado; SALCEDO, Rosio Fernández Baca. Ensino dialógico do projeto arquitetônico em áreas históricas. In: Maria Solange Gurgel de Castro; Fontes, Obede Borges Faria e Rosío Fernández Baca Salcedo (organizadores). Pesquisa em arquitetura e urbanismo : fundamentação teórica e métodos.- São Paulo : Cultura Acadêmica, 2016, p. $47-68$.

Método de ensino do projeto arquitetônico : uma proposta dialógica. In: Marta Enokibara, Nilson Ghirardello e Rosío Fernández Baca Salcedo (org). Patrimônio, paisagem e cidade. Tupã : ANAP, 2016, p. $09-34$.

In: PASCHOARELLI, Luis Carlos; SALCEDO, Rosio Fernández Baca. (Org.). Arquitetura Dialógica no contexto do centro histórico: o método. Bauru, SP: Canal 6. 2015, p. 227-230.

CHOAY, Françoise. A alegoria do patrimônio. São Paulo: Estação Liberdade/Editora Unesp, 2006.

FREIRE, Paulo. Pedagogia do oprimido. 17a edição. Rio de Janeiro: Paz e Terra, 1988. 
